\title{
Stability of pineapple leaf residue chars generated by controlled combustion and by field burning in tropical peat
}

\begin{abstract}
The study was undertaken to determine the decomposition of pineapple leaf residue (PLR) char produced by controlled combustion in the laboratory (CL) and by field burning (FB) with and without added fertilizer in tropical peat over 12 months. Decompositions of both chars with and without added fertilizer fit the three-parameter single exponential decay model. Fertilizer treatment significantly reduced the weight and lignin remainings in the CL and $\mathrm{CF}$ biochars after 12 months. Total $\mathrm{C}$ remaining in the biochar showed an increase in this

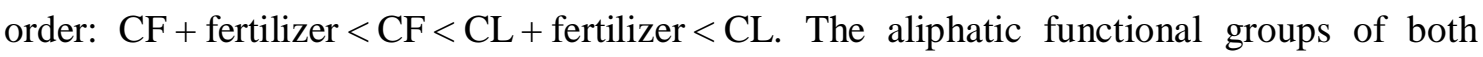
chars transformed to aromatic groups 12 months after application to the peat. The pot study indicates that the total $\mathrm{C}$, recalcitrant fractions and lignin content of char made by CL were higher than the char made by FB. The results suggest that to produce biochar for carbon sequestration purposes, the PLR should be carbonized in a CL process rather than by FB.
\end{abstract}

Keyword: Biomass; Carbon; Char decomposition; Fertilizer addition; Lignin 